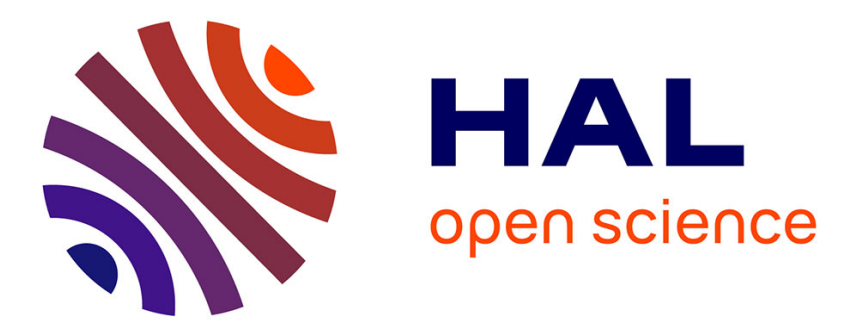

\title{
Imaging visceral adhesion to polymeric mesh using pneumoperitoneal-MRI in an experimental rat model
}

Florence Franconi, Jérome Roux, Céline Lefebvre-Lacoeuille, Laurent Lemaire

\section{To cite this version:}

Florence Franconi, Jérome Roux, Céline Lefebvre-Lacoeuille, Laurent Lemaire. Imaging visceral adhesion to polymeric mesh using pneumoperitoneal-MRI in an experimental rat model. Surgical Endoscopy, 2015, 2014, in press. 10.1007/s00464-014-3843-9 . inserm-01078106

\section{HAL Id: inserm-01078106 https://www.hal.inserm.fr/inserm-01078106}

Submitted on 28 Oct 2014

HAL is a multi-disciplinary open access archive for the deposit and dissemination of scientific research documents, whether they are published or not. The documents may come from teaching and research institutions in France or abroad, or from public or private research centers.
L'archive ouverte pluridisciplinaire HAL, est destinée au dépôt et à la diffusion de documents scientifiques de niveau recherche, publiés ou non, émanant des établissements d'enseignement et de recherche français ou étrangers, des laboratoires publics ou privés. 


\title{
Imaging visceral adhesion to polymeric mesh using pneumoperitoneal-MRI in an experimental rat model
}

\author{
Florence Franconi ${ }^{1}, \mathrm{PhD}$, Jérome Roux ${ }^{2}, \mathrm{MSc}$, Céline Lefebvre-Lacoeuille ${ }^{3,4}, \mathrm{MD}$ and \\ Laurent Lemaire ${ }^{3}, \mathrm{PhD}$ 量
}

Corresponding authors : E-mail: laurent.lemaire@univ-angers.fr

Telephone +33244 688530, Fax +33244688545

\begin{abstract}
Background: Intraperitoneal mesh implantation is often associated with formation of adhesion to the mesh. This experimental study examines the potential of minimally invasive pneumoperitoneal-MRI to assess these adhesions in a preclinical context.

Methods: Uncoated polyethylene terephthalate meshes were placed intraperitoneally in rats, in regard to the caecum previously scraped to promote petechial bleeding and subsequent adhesions. Examinations were performed 2-weeks post mesh implantation using a rodent dedicated high field MRI. Respiratory-triggered T2 weighted images were acquired prior to and after intraperitoneal injection of $\sim 8-10 \mathrm{~mL}$ gas to induce a mechanical stress on the abdominal wall.
\end{abstract}

Results Adhesions are occasionally seen in sham operated rats as opposed to rats receiving polyethylene terephthalate meshes. On high-resolution images, meshes can be detected due to their characteristic net-shape.

1 PRIMEX-CIFAB, Université d'Angers, LUNAM Université, IRIS-IBS, CHU Angers, 4 rue Larrey, 49933 Angers Cedex 9, France

2 Service Commun d'Animalerie HospitaloUniversitaire, Université d'Angers, UFR Sciences médicales, Angers Cedex 1.

${ }^{3}$ UMR-S INSERM 1066, Université d'Angers, IRIS-IBS, CHU Angers, 4 rue Larrey, 49933 Angers Cedex 9, France

${ }^{4}$ Service de Chirurgie Gynécologique - $\mathrm{CHU}$
Angers..
However, evidence of adherence is only found if intraperitoneal gas injection is performed, when a $\sim 1-\mathrm{cm}$ elevation of the abdominal wall is observed. When adherence occurs between the mesh and the caecum, the latter remains in contact with the wall. Looser adherences between visceral tissue and meshes are also observed.

\section{Conclusions}

T2-weighted pneumoperitoneal-MR imaging is a powerful tool for assessing adherence after intraperitoneal mesh implantation. According to the mini-invasive procedure adopted here, this approach may allow a temporal follow-up of adherence fate.

Key words : Ventral hernia repair, MRI, pneumoperitoneum, mesh, adherence.

\section{Introduction}

Ventral hernia is a frequent complication occurring after abdominal surgery with an incidence of 2 to $20 \%[1,2]$. Although ventral hernia repair can be performed by suture, this operation tends to be replaced by the implantation of synthetic meshes either in open or laparoscopic surgical approaches despite possible complications related to prosthesis shrinkage/displacement or abdominal adhesion. Detection of meshes is an important issue, since most commercial prostheses cannot be imaged non-invasively once implanted [3, 4], even though the protein film present at the surface of some of these prostheses can be seen using Amide Proton Transfer 
magnetic resonance imaging (MRI), which therefore allows their detection [5]. However, this detection using MRI is limited in time, as the protein film is resorbed within a few weeks. Numerous experimental studies have been carried out to allow a long term detection by Gadolinium chelate grafting $[6,7]$ or iron oxide embedding $[8,9]$.

On the other hand, detection of adhesions is also a major concern as they may be present in up to $50 \%$ of intra-abdominal surgery cases [10], with a high socio-economic cost [11] and large impact on patients' comfort. The main complications of peritoneal adhesions are small bowel obstructions, chronic abdominal or pelvic pain, infertility and increased risk of intestinal injury in a reoperation. Among the noninvasive techniques applied in clinics, functional Cine MRI and high-resolution ultrasonography appear as the two major imaging techniques used to address this issue. In both cases, the spontaneous abdominal motions induced by respiration are used to track the adherences that impair the normal visceral slide [12-14]. However, prior to being used in humans, numerous preclinical evaluations are required and the paradigm used in clinics to assess abdominal adhesion can not be used since spontaneous visceral slides are too limited.

The aim of this study is to propose a minimally-invasive high-resolution imaging technique to visualize abdominal adhesions and therefore allow a fast and reliable methodology for the screening of new meshes in preclinical rodent models.

\section{Materials and Methods}

\section{In vivo mesh implantation}

The animal study protocol was approved by the local institutional animal care and use committee. Eight female SpragueDawley rats (250-300 g; Angers Hospital Animal Facility) were used in the study. 15 minutes prior to surgery, rats were injected IM with $10 \mu \mathrm{g} / \mathrm{kg}$ Buprenorphine (Vetergesic, Sogeval, France). Under isoflurane anesthesia, polyethylene terephthalate meshes $\left(15 * 25 \mathrm{~mm}^{2}\right)$ were implanted intraperitoneally in 5 rats according to a previously described protocol [15]. Briefly, a 4-cm midline incision was made. The left abdominal wall was reflected, and a $20 * 20-\mathrm{mm}$ surface was denuded by removing the peritoneum and some muscle fibres. A moistened gauze pad was rubbed against the anterior surface of the cecum when the serosal sheath covering the ventral face of the cecum was denuded. Both the abdominal wall and the cecum were lightly scraped with a scalpel blade to promote petechial bleeding and were then exposed and allowed to air dry for 5 min. The rest of the abdominal contents were protected from drying by placing moist gauze over them during the drying period. A piece of the mesh was hydrated and placed immediately between the defects on the cecum and the abdominal wall. The mesh was secured to the abdominal wall by suturing the four corners using a 6-0 silk suture. The middle incision and the skin were closed with a running 6-0 silk suture. Sham operated rats $(n=3)$ underwent the same procedure excepted the mesh implantation. All animals were then allowed to recover from surgery and received, 6 and 24 hours later, an additional injection of buprenorphine, delivered this time subcutaneously. During the whole study, the animals were housed under 12-h light/dark cycle conditions at constant temperature, and humidity. The animals received a complete diet and water ad libitum.

\section{Pneumoperitoneal-MRI}

To reduce unwanted peristaltic movements that can lead to MRI artefacts, the rats were fasted $12 \mathrm{~h}$ prior to imaging sessions. Under isoflurane anesthesia, a 5-mm skin incision was performed on the right side of the rat abdomen. A 2-mm outer diameter trocar was used to pass through the muscular layer, allowing the introduction of a 1$\mathrm{mm}$ diameter polypropylene catheter, which was then used for the injection of $0.22 \mu \mathrm{m}$ filtered air within the rat abdomen in order to induce an abdominal distension. Rats were positioned within the scanner in the 
supine position. All MR studies were performed with a Biospec Avance III MR scanner (Bruker Biospin, Wissembourg, France) using a $20 \mathrm{~cm}$ bore 7T magnet equipped with BGA12S gradient/shim system capable of $675 \mathrm{mT} / \mathrm{m}$ maximum gradient strength. A $72-\mathrm{mm}$ diameter volume coil was used. After a set of scout images, 3 orthogonal anatomical set of images were acquired. A standard multi-slice multi-spin echo sequence [16] was used with the following parameters: effective echo time TE $=27 \mathrm{~ms}$ with an echo train of 8 ; repetition time TR $1500 \mathrm{~ms}$ depending on the breathing rate when acquisitions are triggered; slice thickness $=2 \mathrm{~mm}$; field-of-view $=$ $5.5 * 5.5 \mathrm{~cm}$; matrix $256 * 256$ leading to an in-plan resolution of $214 * 214 \mu \mathrm{m}$. According to the repetition time used, up to 9 slices could be acquired per respiratory cycle. Each orthogonal set was acquired in $\sim 6 \mathrm{~min}$.

After acquiring a first set of images with no stress being applied to the rat abdomen, ca. $10 \mathrm{~mL}$ air were pushed to induce a displacement of the abdominal wall.

\section{Results}

Evaluation of Adhesions in a sham operated rat.

Figure 1 shows MR images acquired perpendicular to the rat spinal cord (axial view - frames A \& B) or along the cord (sagittal view - frames C \& D) prior to (frames A \& C) or after gas injection (frames C \& D).

As the caecum is naturally in contact with the abdominal wall, it is not possible to highlight any potential adherences without applying stress on the abdominal wall. In the presented case, injection of $8 \mathrm{~mL}$ gas induces a significant elevation of the abdominal wall. As illustrated in figure 1C\&D, adherences between the abdominal wall and caecal abrasion can be detected (arrows) in this shamoperated rat, which underwent the entire surgical procedure, but without prosthesis implantation. The adherence extent is limited to the proximal part of the caecum over a width of about $8 \mathrm{~mm}$ and less than $2 \mathrm{~mm}$ long. The limited adherence is confirmed by the autopsy (frame E). Adherences between the caecum and the abdominal in this sham protocole were only observed in 1 case out of 3 .
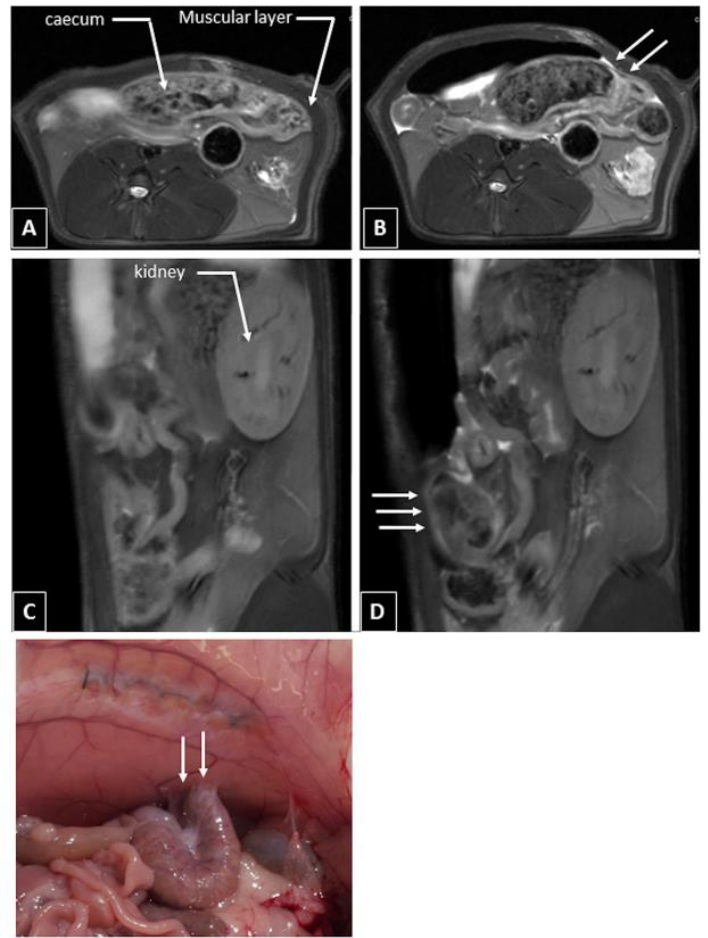

Figure 1: T2-weighted MR images of a sham operated rat. A \&C show axial and sagittal view, respectively, acquired prior to stress on the abdominal wall. $B \& D$ correspond to the same abdominal area after intraperitoneal injection of gas. (E) shows the situation at autopsy.

\section{Partial adhesions after mesh implantation:}

Prior to gas injection, adherences between the prosthesis and the caecum cannot be observed since the latter is naturally in contact with the abdomen wall. Due to the very high image resolution, the prosthesis was nevertheless detected as a hyperintense dashed line (figure 2, frame A). In the pneumoperitoneal -MRI axial data set, it can be seen that the caecum does not fully adhere to the prosthesis (frame B). Analysis of contiguous images allows an estimation of the extent of the adherences at about $10 \mathrm{~mm}$, but with respect to the initial size of the prosthesis $\left(25^{*} 15 \mathrm{~mm}\right)$ and its lateral position, it is possible that adherences are also present between the abdominal wall and the caecum. To test this hypothesis, sagittal images, (i.e., perpendicular images) were acquired. 

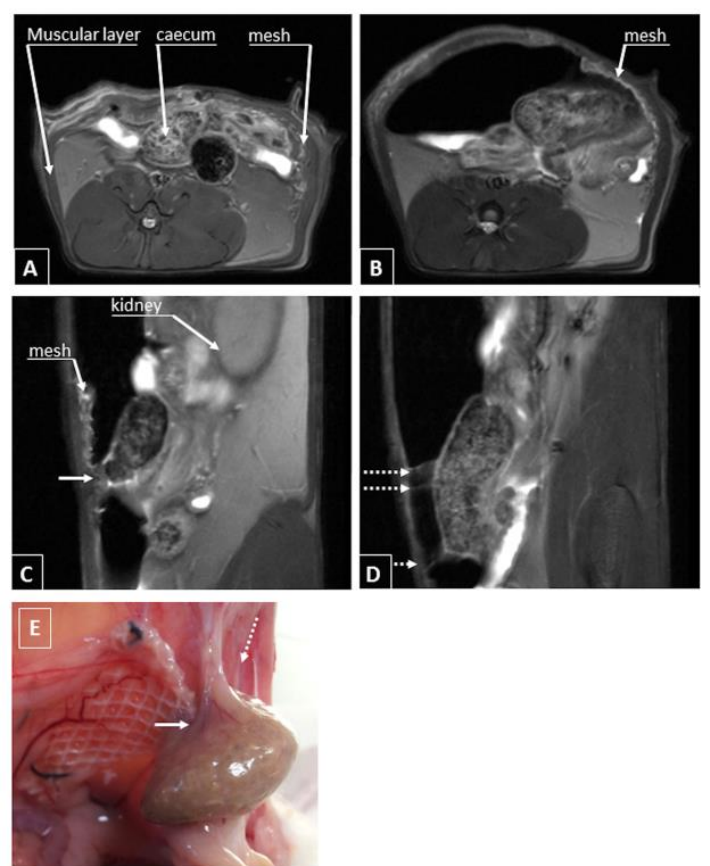

Figure 2: T2-weighted MR images of an operated rat implanted with a $25 * 15 \mathrm{~mm}$ polyethylene terephthalate prosthesis. Frame A shows an axial view, acquired prior to stress on the abdominal wall. Frame $B$ corresponds to an axial view after intraperitoneal injection of gas illustrating the partial adhesion between caecum and prosthesis. Frames $C \& D$ shows sagittal views after gas injection, illustrating respectively, adherences prosthesis/caecum (plain arrow) and caecum abdominal wall (dashed arrow). Frame $E$ presents the situation at autopsy with a grading of 2 according to the Blauer and Collins classification.

On the sagittal view (frame $C$ ), the prosthesis is unambiguously seen with its characteristic net-shape. Adherences between the caecum and the prosthesis are evident and the analysis of the contiguous slices showed that they are limited to a length of about $3-4 \mathrm{~mm}$. On frame $D$, these adherences no longer occur between the prosthesis and the caecum but between the caecum and the slightly scraped abdominal wall (dashed arrows), having a length of about $10 \mathrm{~mm}$. Taking all the evidence together, from the MR images, it can be estimated that adherences are present over an area of about $10 \mathrm{~mm} * 3 \mathrm{~mm}$. This limited area is confirmed at the rat autopsy (frame E) and can be graded at stage 3 according to the Blauer and Collins classification $[17,18]$.

\section{Heterogeneous Adhesions.}

Prior to any gas injection, the natural position of the caecum in contact to the abdominal wall does not allow detection of any adherences. On the post-gas images, thin hyperintense lines are detected between the edge of the prosthesis/abdominal wall and the underlying tissues, suggesting the presence of adherences between the prosthesis and the fatty tissue as previously observed (figure 3, frame A). According to the sagittal view (frame $C$ ), these adherences occur between the edge of the prosthesis and the underlying tissues.
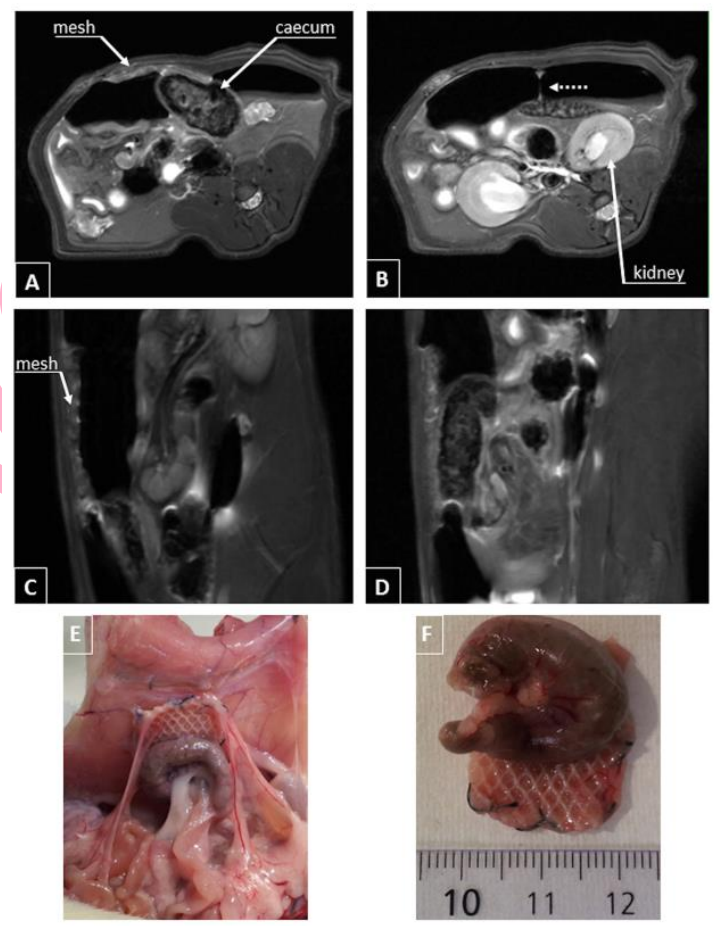

Figure 3: T2-weighted MR images of an operated rat implanted with a polyethylene terephthalate prosthesis after intraperitoneal gas injection. (A \& B) are axial views showing respectively adhesions. $C \& D$ correspond to perpendicular views showing prosthesis/caecum (plain arrow) and prosthesis/underling tissue (dashed arrow) adhesions. ( $E$ \& F) shows the situation at autopsy with a grading of 4 according to the Blauer and Collins classification.

Adherences between the prosthesis and the caecal abrasion are unambiguously seen in frames $B \& D$, which show an overlap of $\sim 18 \mathrm{~mm}$ between prosthesis and caecum, (i.e. 9 slices of $2 \mathrm{~mm}$ ), with a measured width of $6 \mathrm{~mm}$. At autopsy (frame $E \& F$ ), the interaction between the prosthesis and the caecum appears 
to correspond to about the entire length of the prosthesis over half of its width (i.e. $20 \mathrm{~mm}^{*} 8 \mathrm{~mm}$ ). The presence of thin bridges with the fatty tissue is confirmed and the maxima global grading is 4 according to the Blauer and Collins classification.

\section{Discussion}

Mesh implantation in hernia repair leads to adhesion. The assessment of new meshes or the comparison of meshes in pre-clinical models often required animal sacrifice to observe these adhesions and quantify their extent [19-21], even though alternative approaches, based on clinical practice, may be of interest due to their non-invasive characteristics and therefore their potential for sequential follow-up [12-14]. For example, functional Cine MRI and high-resolution ultrasonography have been extensively used in clinical practices; with both methods, using the spontaneous abdominal motion induced by respiration to tract the adherences that impair the normal visceral slide. However, in preclinical rodent models, spontaneous motions are too limited to allow a direct application. As a consequence, one has to amplify these motions to track the adherences. As far as MRI is concerned, manual actions cannot be easily performed on the animal abdomen because of its position in the middle of the magnet. However, a simple mechanical action can be carried out using a pneumoperitoneal approach previously validated in large animals [22], as well as in rodents [23, 24]. As shown in all cases discussed here, the injection of gas within the rat abdomen leads to its elevation. The injected volume could be limited to $\sim 10-\mathrm{mL}$ in a $250 \mathrm{~g}$ rat, which would produce an elevation of ca. $1 \mathrm{~cm}$ of the abdominal wall, being sufficient to unambiguously reveal adherences between meshes and caecum in this caecal abrasion model. Despite being of heterogeneous extent, this model leads to high adherences between caecum and prosthesis, along with looser adherences between visceral tissue and prosthesis. High adherences have been previously explored in a peritoneal abrasion model using, instead of gas, an injection of clinically approved $4.25 \%$ dextrose peritoneal dialysis fluid (Fresenius Medical Care, Bad Homburg, Germany) [25]. In this previous study, the fluid was seen to expand within the abdominal cavity and its non-uniform distribution, highlighted the adherences. However, this solution gave rise to a hyperintense signal in which thin adhesive bands might be difficult to see due to a lack of contrast. In our approach, the injected gas does not create any MR signal and the biological tissue, even if thin, yields to a signal that can easily be seen owing to the high contrast. The approach developed here to track adherences between prosthesis and tissue may also be of interest when improved surgical procedures and therapies are tested with a view to reducing adherences $[17,24]$.

\section{Conclusion}

High resolution MRI associated with pneumoperitoneum in rodent appears as a fast and effective technique for assessing tissue adherence after mesh implantation. This minimally-invasive approach may be of significant interest when a temporal follow-up is required as is usually the case during preclinical evaluation of abdominal prosthesis.

Acknowledgments The authors are grateful to Dr. O. Lefranc (Covidien, Trevoux, France) for the generous gift of the polyethylene terephthalate textile and Ms. A. Mourlan (Service Commun d'Animalerie Hospitalo-Universitaire, Université d'Angers) for peri-operative animal care. Dr. M.S.N Carpenter postedited the English style.

Disclosures F. Franconi, J. Roux, C. Lefebvre and L. Lemaire have no conflicts of interest or financial ties to disclose. 


\section{Bibliography}

1. Burger JW, Luijendijk RW, Hop WC, Halm JA, Verdaasdonk EG, Jeekel J (2004) Long-term follow-up of a randomized controlled trial of suture versus mesh repair of incisional hernia. Annals of surgery 240:578-583; discussion 583575

2. Shankaran V, Weber DJ, Reed RL, 2nd, Luchette FA (2011) A review of available prosthetics for ventral hernia repair. Annals of surgery 253:16-26

3. Bellon JM, Rodriguez M, Gomez-Gil V, Sotomayor S, Bujan J, Pascual G (2012) Postimplant intraperitoneal behavior of collagen-based meshes followed by laparoscopy. Surgical Endoscopy and Other Interventional Techniques 26:27-35

4. Pascual G, Perez-Kohler B, Rodriguez $M$, Sotomayor S, Bellon JM (2014) Postimplantation host tissue response and biodegradation of biologic versus polymer meshes implanted in an intraperitoneal position. Surgical Endoscopy and Other Interventional Techniques 28:559-569

5. Franconi F, Roux J, Garric X, Lemaire L (2014) Early postsurgical visualization of composite mesh used in ventral hernia repair by amide proton transfer MRI. Magn Reson Med 71:313317

6. Blanquer S, Guillaume O, Letouzey V, Lemaire L, Franconi F, Paniagua C, Coudane J, Garric X (2012) New magnetic-resonance-imagingvisible poly(epsilon-caprolactone)-based polyester for biomedical applications. Acta biomaterialia 8:1339-1347

7. Guillaume O, Blanquer S, Letouzey V, Cornille A, Huberlant S, Lemaire L, Franconi $F$, de Tayrac R, Coudane J, Garric X (2012) Permanent polymer coating for in vivo MRI visualization of tissue reinforcement prostheses. Macromolecular bioscience 12:1364-1374

8. Kramer NA, Donker HC, Otto J, Hodenius M, Senegas J, Slabu I, Klinge U, Baumann M, Mullen A, Obolenski B, Gunther RW, Krombach GA (2010) A concept for magnetic resonance visualization of surgical textile implants. Invest Radiol 45:477-483

9. Kuehnert N, Kraemer NA, Otto J, Donker HC, Slabu I, Baumann M, Kuhl CK, Klinge U (2012) In vivo MRI visualization of mesh shrinkage using surgical implants loaded with superparamagnetic iron oxides. Surgical endoscopy 26:1468-1475
10. Levrant SG, Bieber EJ, Barnes RB (1997) Anterior abdominal wall adhesions after laparotomy or laparoscopy. The Journal of the American Association of Gynecologic Laparoscopists 4:353-356

11. Tingstedt B, Isaksson J, Andersson R (2007) Long-term follow-up and cost analysis following surgery for small bowel obstruction caused by intra-abdominal adhesions. The British journal of surgery 94:743-748

12. Zinther NB, Zeuten A, Marinovskij E, Haislund $M$, Friis-Andersen $H$ (2010) Detection of abdominal wall adhesions using visceral slide. Surgical endoscopy 24:3161-3166

13. Zinther NB, Fedder J, Friis-Andersen H (2010) Noninvasive detection and mapping of intraabdominal adhesions: a review of the current literature. Surgical endoscopy 24:26812686

14. Mussack T, Fischer T, Ladurner R, Gangkofer A, Bensler S, Hallfeldt KK, Reiser M, Lienemann A (2005) Cine magnetic resonance imaging vs high-resolution ultrasonography for detection of adhesions after laparoscopic and open incisional hernia repair: a matched pair pilot analysis. Surgical endoscopy 19:1538-1543

15. Harris ES, Morgan RF, Rodeheaver GT (1995) Analysis of the kinetics of peritoneal adhesion formation in the rat and evaluation of potential antiadhesive agents. Surgery 117:663-669

16. Hennig J, Nauerth A, Friedburg H (1986) RARE imaging: a fast imaging method for clinical MR. Magn Reson Med 3:823-833

17. Yilmaz HG, Tacyildiz IH, Keles C, Gedik E, Kilinc N (2005) Micronized purified flavonoid fraction may prevent formation of intraperitoneal adhesions in rats. Fertility and sterility 84 Suppl 2:1083-1088

18. Blauer KL, Collins RL (1988) The effect of intraperitoneal progesterone on postoperative adhesion formation in rabbits. Fertility and sterility 49:144-149

19. Di Loreto FP, Mangione A, Palmisano E, Cerda JI, Dominguez MJ, Ponce G, Bernaus M, Gaffuri S, Torresi G, Bianco S (2013) Dried human amniotic membrane as an antiadherent layer for intraperitoneal placing of polypropylene mesh in rats. Surgical endoscopy 27:1435-1440

20. Ditzel $M$, Deerenberg EB, Grotenhuis $N$, Harlaar JJ, Monkhorst K, BastiaansenJenniskens YM, Jeekel J, Lange JF (2013) 
Biologic meshes are not superior to synthetic meshes in ventral hernia repair: an experimental study with long-term follow-up evaluation. Surgical endoscopy 27:3654-3662

21. Schreinemacher $\mathrm{MH}$, van Barneveld $\mathrm{KW}$, Dikmans RE, Gijbels MJ, Greve JW, Bouvy ND (2013) Coated meshes for hernia repair provide comparable intraperitoneal adhesion prevention. Surgical endoscopy 27:4202-4209

22. Sanchez-Margallo FM, Moyano-Cuevas JL, Latorre R, Maestre J, Correa L, Pagador JB, Sanchez-Peralta LF, Sanchez-Margallo JA, Uson-Gargallo J (2011) Anatomical changes due to pneumoperitoneum analyzed by MRI: an experimental study in pigs. Surgical and radiologic anatomy : SRA 33:389-396

23. Miyano G, Yamataka A, Doi T, Okawada $M$, Takano Y, Kobayashi H, Lane GJ, Miyano T (2006) Carbon dioxide pneumoperitoneum prevents intraperitoneal adhesions after laparotomy in rats. J Pediatr Surg 41:10251028

24. Corona R, Binda MM, Mailova K, Verguts J, Koninckx PR (2013) Addition of nitrous oxide to the carbon dioxide pneumoperitoneum strongly decreases adhesion formation and the dose-dependent adhesiogenic effect of blood in a laparoscopic mouse model. Fertility and sterility 100:1777-1783

25. Guo H, Leung JC, Cheung JS, Chan LY, Wu EX, Lai KN (2009) Non-viral Smad7 gene delivery and attenuation of postoperative peritoneal adhesion in an experimental model. The British journal of surgery $96: 1323-1335$ 